\title{
Design of a Mobile Application for the School Enrollment Process in Order to Prevent Covid-19
}

\author{
Alexi Delgado ${ }^{*}, 1$, Enrique Lee Huamaní ${ }^{2}$, Alfredo Chiara-Sotomayor ${ }^{3}$, Florencio Roman-Casahuamán ${ }^{3}$ \\ ${ }^{1}$ Mining Engineering Section, Pontificia Universidad Católica del Perú, 15088, Perú \\ ${ }^{2}$ Image Processing Research Laboratory (INTI-Lab), Universidad de Ciencias y Humanidades, 15307, Perú
}

${ }^{3}$ Systems Enginerring Program, Universidad de Ciencias y Humanidades, 15307, Perú

\begin{tabular}{l} 
A R T I C L E I N F \\
\hline Article history: \\
Received: 19 August, \\
Accepted: 09 November, \\
Online: 14 December, \\
\hline Keywords: \\
Android \\
Registration process \\
Mobile Application \\
Agile Methodology \\
Health
\end{tabular}

\section{Introduction}

In December 2019, a large and growing outbreak of a new coronavirus was reported in Wuhan, Hubei Province, China [1]. The global COVID-19 pandemic spreads easily to people nearby, especially in crowds with mobile people (for example, city centers). A widely accepted strategy to mitigate its spread is social distancing, avoiding crowds [2].

*Corresponding Author: Alexi Delgado, kdelgadov@pucp.edu.pe

\begin{abstract}
A B S T R A C T
In 2020, a great change occurred around the world due to the covid-19 pandemic, daily activities were restructured and thanks to technological advance it has been an ideal means to carry out remote work. With regard to education in Peru, it was paralyzed for a long time and only obtained in later months the option of video offerings software for the interaction of teachers and students, given these new activities carried out. In schools, we are proposing a mobile application prototype that is adaptable to any school in Perú in order to facilitate the registration process of parents for their children due to the global crisis that we are going through. Parents will have a follow-up and ideal control for your children. The methodology that will help us to carry out this application will be the agile methodology with the scrum framework, since it adapts to the needs of the client, and to the constant changes in the development process of the mobile application. Since high student demand requires fast delivery of the application with cost and time efficiency. The mobile application to which students and tutors will be automatically transferred will have easy access to use it in the registration processes and in their academic controls. Our task is created in three points of view, student, tutor and teacher. The student was validated, with the registration or registration and login for the students already registered. Where the student can validate their personal data already registered and see their school monitoring, such as grades, attendance, courses, schedules and payments. The result obtained is the proposal of a productive approach, optimizing the license plate control processes, through a mobile application, where each agent can perform this function, and thus reduce the risk of contagion in these moments of pandemic. And so, in this way, interconnect all the enrollments, the benefactors in a system, saving their information and the data of the students. With these results, it will be of great benefit for the school to minimize the time and thus increase the competitiveness between the schools, also for the parents and for the students who despite the difficulties continue to progress in life.
\end{abstract}

One of the first broad-spectrum measures has been the closure of educational centers at all levels, which has affected $91.3 \%$ of the total number of students enrolled in the world: more than 1.5 billion people have been left without power attend their face-toface classes, according to UNESCO [3].

Several methodologies were found for the construction of the mobile application, but in this case the Scrum methodology was used, which is a framework for agile software development that has expanded to other industries.It is a process in which a set of 
good practices are applied on a regular basis to work collaboratively, in teams and to obtain the best possible project results. The evolution of software development methods has taken place since 1970. The Agile Methodology also offers services to companies to create the right product that makes them aggressive in the market [4], [5]. The Agile methodology is considered one of the best approaches for the development of mobile applications [6]. Many unavoidable developmental changes could also be identified [7]. Finally, Balsamiq was chosen for the development of the design, as it is useful for communicating ideas [8].

This article uses the design of a mobile application to analyze the enrollment and school monitoring process in the Comas District [9], in order to allow parents to access enrollment without the need to go to schools. It will also include a search and database of school monitoring information per student.

The objective of this research work is to help parents maintain control of their children at school, using a tool that will be easy to use for the different processes that the institution handles. In addition, with the study of information that we carry out it will allow us to avoid spreading the coronavirus.

The present work is structured in the following way, in the next section number II the methodology used for the construction of the application will be described in detail. In section III the results obtained will be evidenced and finally in section IV the own results will be discussed and the conclusions will be presented.

\section{Methodology}

In this section we will detail what steps will be followed for the development of the mobile application, so we will use the Agile Scrum Methodology as shown in Figure 1 which explains in a general way the behavior of Scrum, using this methodology is advantageous due to the flexibility in the requirements and ease in adapting to changes.

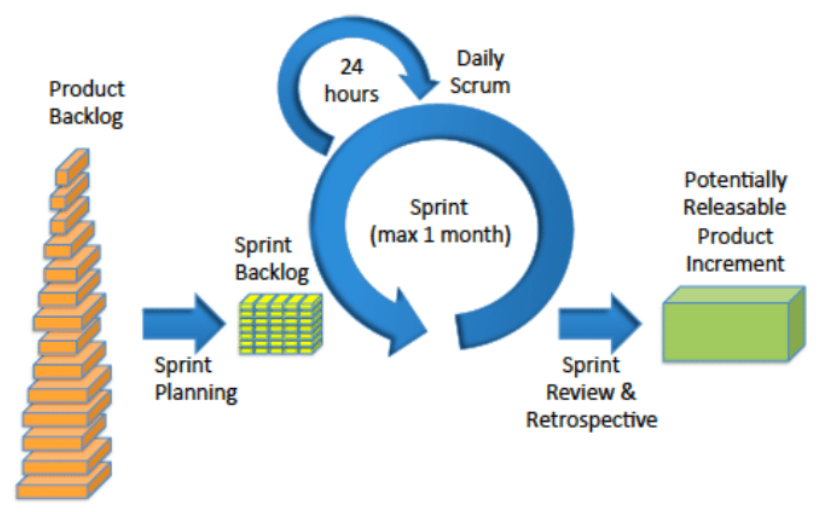

Figure 1: Diagram of the Scrum methodology

\subsection{Analysis}

Agile Scrum Methodology: As Troy Dimes wrote, scrum is like a lifeline for those companies that face difficulties in not even having a methodology to develop software. Scrum is a framework for creating complex software and delivering it on time in a much simpler way. Scrum is not a methodology; it is a reference framework within the agile software development methodology, which will enable it to create excellent software, through the application of a set of guidelines to be followed by work teams and the use of specific roles [10].

Scrum defines three roles: The Scrum master, the product owner, and the development team. The scrum master's role is to ensure that the team is adopting the methodology, its practices and values and norms; is the team leader, but does not manage development [11]. For its part, the development team is responsible for converting what the customer wants, the Product Backlog, into functional iterations of the product; the development team does not have hierarchies, and all its members have the same level and position: developer. The optimal team size is between three and nine people [12].

\section{Sprint planning}

This stage takes place at the Sprint Planning meeting where the activities to be carried out are defined. This activity takes eight hours for a month of Sprint. If Sprint is shorter, the time is allocated proportionally [12].

\section{Development stage}

At this stage, the sprint managers must guarantee that last minute changes that affect the objectives are not generated. In addition, they must ensure that they meet the established deadlines.

\section{Sprint review}

The Sprint Review occurs at the end of the Sprint and lasts for four hours for a one-month project (or a proportion of that time if the duration is shorter). At this stage: the project owner reviews what was done, identifies what was not done, and discusses the Product Backlog; the development team counts the problems it found and the way they were solved, and shows the product and how it works.

\section{Feedback}

Empirical process control is retrospective and not predictive, which would imply that decisions are made based on evidence and knowledge is nurtured in experience. The lessons to be learned in this stage will allow us to learn how sprints can be much more effective and agile.

\subsection{Design and tools}

\section{Programming platform (Android Studio)}

It is the official integrated development environment for the Android platform, is one of the most used IDES for the development of Android applications due to its intuitive interface for the arrangement of the elements used in the architecture of the project [13].

\section{Database manager (Microsoft SQL Server)}

The storage and management of data is mainly done through the database of the business management system, so it is very important to study the design and implementation of the database in the system [14]. 


\section{Design Tool (Balsamiq Wireframes)}

In this research, the Balsamiq Mockups tool is used as a tool that will facilitate the development of the project's prototypes [15].

\subsection{Procedure}

\section{Product blacklog}

The Product Backlog is a list, ordered by value, risk, priority and need of the requirements that the product owner defines, updates and orders. The list has as a particular characteristic that it is neveFinished, since it evolved during the development of the project [12].

\section{Sprint backlog}

It is the task list that contains selected tasks from the Product Backlog, in which it subdivides the user stories that describe the functionalities that make up the project. This listing is defined and estimated at the Sprint Planning meeting at the start of the iteration [16].

\section{Sprint planning meeting}

It is the Sprint planning meeting based on the Product Backlog and they participate: Product Owner (responsible for the subject) who prioritizes the tasks to include in the Sprint Backlog, the Scrum Master and the Development Team [16].

\section{Case study}

This section will develop what is the planning of the sprints of each of the modules and the estimates of the times in which it is being carried out in the mobile application development stage.

\subsection{Sprint planning}

- As a user you can enter the application through an account generated by the school.
- As a user you can view the courses with their grades, schedules and pensions.

- As a user, you may be able to register me once you have paid the registration fee.

- As a proxy you can know the names of the teachers with their respective courses that my son will take.

- As a proxy you can know the respective qualifications of my son with their respective states.

- As administrator, you can keep track of student pensions.

- As administrator you can generate detailed reports of each student.

\subsection{Development Stage}

\section{Time estimation}

In this phase we will see the duration of each of the sprints as shown in Table 1.

\section{Product scope}

This is the estimate of the time it takes for the equipment to be able to have the user's history points, for which the estimates of the scope of the equipment will be noted in Figure 2.

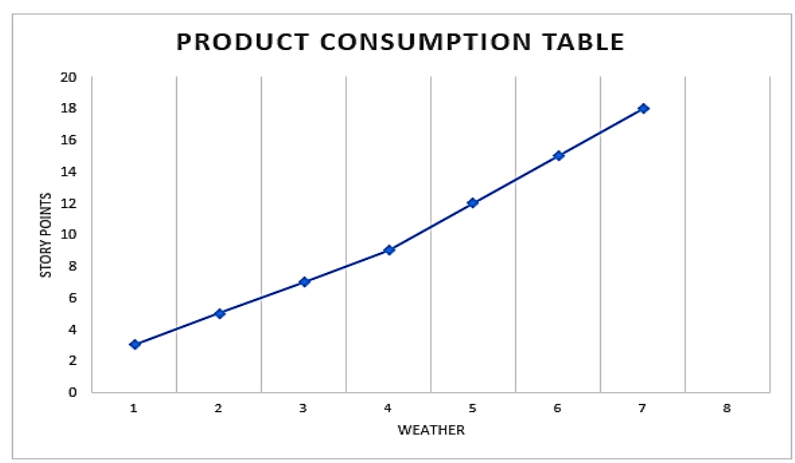

Figure 2: Product scope

Table 1: Duration of Sprints

\begin{tabular}{|l|c|c|c|}
\hline \multicolumn{1}{|c|}{ Name } & Duration & Start & Final \\
\hline $\begin{array}{l}\text { Mobile Application for the } \\
\text { Enrollment Process }\end{array}$ & 3 months & $01 / 06 / 2020$ & $01 / 10 / 2020$ \\
\hline 1. User Module & 2 weeks & $01 / 06 / 2020$ & $15 / 06 / 2020$ \\
\hline 2. Enrolment Module & 2 weeks & $16 / 06 / 2020$ & $30 / 06 / 2020$ \\
\hline 3. Schedule Module & 2 weeks & $31 / 06 / 2020$ & $13 / 07 / 2020$ \\
\hline 4. Courses Module & 2 weeks & $14 / 07 / 2020$ & $27 / 07 / 2020$ \\
\hline 5. Ratings Module & 2 weeks & $28 / 07 / 2020$ & $10 / 07 / 2020$ \\
\hline 6. Pension Module & 4 weeks & $10 / 07 / 2020$ & $10 / 08 / 2020$ \\
\hline 7. Reporting Module & 5 weeks & $11 / 08 / 2020$ & $31 / 09 / 2020$ \\
\hline
\end{tabular}




\subsection{Prototypes of the mobile application}

In this stage we will see the creation of the mobile application design that we will carry out and we will detail the functions that each of the modules will have as we see in Figure 3 (a), Figure 3 (b), Figure 3 (c) and Figure 3 (d).

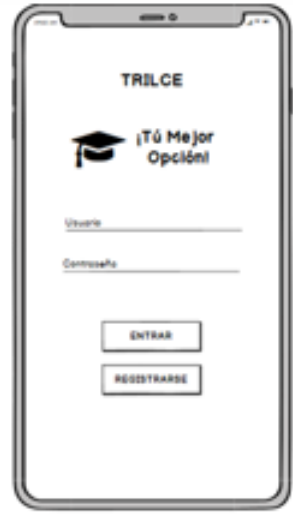

(a) User module

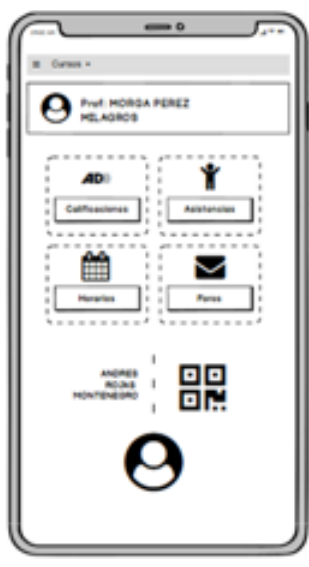

(c) Academic module

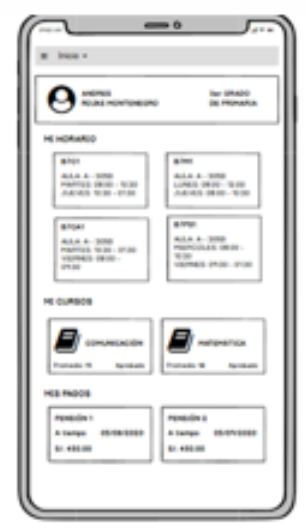

(b) Registration module

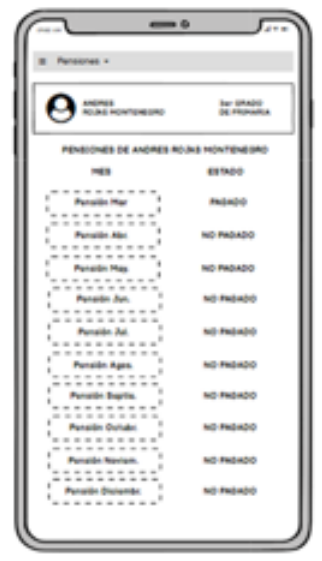

(d) Pension module
Figure 3: Prototype phase of the mobile application

\section{Increment 1: Main Start}

This increase shows the start of the application which, if we have a user already generated by the institution, we could enter the account that maintains personal data of the students Figure 3 (a).

\section{Increment 2: Enrollment module}

This increase shows the process that must be carried out to enroll each student, and as a requirement to proceed, they would have to pay the enrollment for the school year Figure 3 (b).

\section{Increment 3: Detailed courses module}

In this increase it will show the detailed course with its qualifications, assists, schedules and forums, in addition to having a QR code to download the report Figure 3 (c).

\section{Increment 4: Pension module}

In this increase it shows the pensions of each student, detailed by month and the state if it is already canceled or even just canceled Figure 3 (d).

\section{Results and discussion}

\subsection{About the case study}

Compared to other research works, we have observed the design of the work of an Android mobile application for an online Travel Agency, where the use of the NinjaMock tool is specified, where we can see that, on the contrary, its interface does not provides a professional visual finish, increasingly difficult to use [17].

The google API services will be used to obtain the latitude and longitude of the reported location [18]. The importance of the interface is a means for the user to interact with the software and hardware. The interface will help the user to interact with the system much easier than with the old method of giving a command at the command prompt. The following image is the Trusted Halal interface. Malaysia Cosmetic Products System Application [19] [20].

Due to the covid-19 pandemic, enrollment in Peru was $7,834,543$, unlike last year, which was $8,024,672$. Figure 4 extracted from the Ministry of Education [21] shows the number of enrollments in 2020 and a large decrease in enrollment is observed, therefore the proposal of this research will help students to enroll successfully using mobile applications.

\begin{tabular}{|c|c|c|c|}
\hline \multicolumn{2}{|c|}{ URBANO } & RURAL & \multirow{2}{*}{$\begin{array}{l}\text { TOTAL } \\
7,834,543\end{array}$} \\
\hline $6,637,116$ & BÁSICO REGULAR* & $1,197,427$ & \\
\hline $1,336,742$ & INICIAL' & 292,411 & $1,629,153$ \\
\hline $3,021,779$ & PRIMARIAO & 614,344 & $3,636,123$ \\
\hline $2,278,595$ & SECUNDARIA & 290,672 & $2,569,267$ \\
\hline 13,161 & BÁSICA ESPECIAL* & 63 & 13,224 \\
\hline 214,004 & BÁSICA ALTERNATIVA** & 1,172 & 215,176 \\
\hline 248,402 & TÉCNICO PRODUCTIVO** & 3,647 & 252,049 \\
\hline 521,353 & SUPERIOR NO UNIVERSITARIA** & 4,975 & 526,328 \\
\hline \multicolumn{3}{|c|}{ SUPERIOR UNIVERSITARIA* } & $1,492,470$ \\
\hline
\end{tabular}

Figure 4: Statistical data of enrolled in 2020 under the covid-19 pandemic

\subsection{About the methodology}

The tool used in the present work, which is Balsamiq Mockups, is easier and more adaptable to any user, and that shows us a good effectiveness before its prototypes made. In Balsamiq Mockups, mobile applications are designed in a smarter and easier way [22]. We have observed as an important factor in a project and the first decision of the application is the development prototype therefore the prototyping software Balsamiq Mockups served as a benefit to be able to create our Wireframes easily and quickly [23].

Riadh proposed designing the notification system using GCM (Google Cloud Messaging) of the Android app and connecting to the website and providing information that helps instructor to select who will send notification [24].

In this project, the methodology to be used is Agile Scrum Methodology. Scrum is a lightweight project management framework with the ability to iteratively and incrementally control and manage all types of projects. Through use. The "Product 
Owner" Scrum methodology will work closely with the team to detect and prioritize system functionality [25].

Differences in Methodologies: This part will detail the differences of using the agile methodology, as opposed to using other methodologies that exist. Table 2 will detail the differences that each methodology will have.

Table 2: Traditional Methodology vs Agile Methodology

\begin{tabular}{|c|c|}
\hline Traditional methodologies & Agile methodologies \\
\hline Predictive & Adaptive \\
\hline Process-oriented & People-oriented \\
\hline Rigid process & Flexible process \\
\hline $\begin{array}{c}\text { It is conceived as a } \\
\text { project }\end{array}$ & $\begin{array}{c}\text { A project is subdivided } \\
\text { into several smaller } \\
\text { projects. }\end{array}$ \\
\hline $\begin{array}{c}\text { Little communication } \\
\text { with the client }\end{array}$ & $\begin{array}{c}\text { Constant } \\
\text { client. }\end{array}$ \\
\hline $\begin{array}{c}\text { Software delivery at the } \\
\text { end of development. }\end{array}$ & $\begin{array}{c}\text { Constant software } \\
\text { deliveries }\end{array}$ \\
\hline $\begin{array}{c}\text { Extensive } \\
\text { documentation }\end{array}$ & \begin{tabular}{c} 
Little documentation \\
\hline
\end{tabular} \\
\hline
\end{tabular}

\section{Conclusions}

In this research we designed the proposal of a mobile application, helping to achieve a better solution at the time of registration of enrollment and monitoring of students.

This proposal does not try to meet one level but to seek a comprehensive solution in the short term and can be adapted to any educational institution as has been determined in Table 2 with respect to the duration of the Spring. This work can be improved and will be carried out when they go through the final users in which the satisfaction of the users will be determined with statistical data. We can conclude that the design proposal of the mobile application will be of great benefit to parents when registering their children and monitoring and controlling their daily activities, a proposal that is being promoted in schools in Lima, Peru.

\section{References}

[1] C. Huang et al., "Clinical features of patients infected with 2019 novel coronavirus in Wuhan, China," The Lancet, 395(10223), 497-506, 2020, doi:10.1016/S0140-6736(20)30183-5.

[2] Centers for Disease Control and Prevention, Coronavirus (COVID-19), 2019.

[3] UNESCO, Education: From disruption to recovery, 2019.

[4] B. Mathur, S.M. Satapathy, "An analytical comparison of mobile application development using agile methodologies," Proceedings of the International Conference on Trends in Electronics and Informatics, 4, 1147-1152, 2019, doi:10.1109/icoei.2019.8862532.

[5] P. Abrahamsson, A. Hanhineva, H. Hulkko, T. Ihme, J. Jäälinoja, M. Korkala, J. Koskela, P. Kyllönen, O. Salo, "Mobile-D: An agile approach for mobile application development," Proceedings of the Conference on ObjectOriented Programming Systems, Languages, and Applications, 174-175, 2004, doi:10.1145/1028664.1028736.

[6] S. Holla, M.M. Katti, "ANDROID BASED MOBILE APPLICATION DEVELOPMENT and its SECURITY," International Journal of Computer $\begin{array}{lllll}\text { Trends and } \quad \text { Technology, } & \text { 3(3), }\end{array}$ doi:10.1080/10304312.2012.706462.

[7] A. Cockburn, L. Williams, Agile Software Development: It's about Feedback and Change, IEEE Computer Society: 39-43, 2003.

[8] I. Bouchrika, L. Ait-Oubelli, A. Rabir, N. Harrathi, "Mockup-based navigational diagram for the development of interactive web applications," ACM International Conference Proceeding Series, (7), 27-32, 2013, doi: $10.1145 / 2503859.2503864$.

[9] R.C. Jisha, M.P. Mathews, S.P. Kini, V. Kumar, U. V. Harisankar, M. Shilpa, "An Android Application for School Bus Tracking and Student Monitoring System," International Conference on Computational Intelligence and Computing Research, 1-4, 2018, doi:10.1109/ICCIC.2018.8782320.

[10] A. Mundra, S. Misra, C.A. Dhawale, "Practical scrum-scrum team: Way to produce successful and quality software," International Conference on Computational Science and Its Applications, 119-123, 2013, doi:10.1109/ICCSA.2013.25.

[11] K. Schwaber, J. Sutherland, The Scrum Guide: The Definitive The Rules of the Game, 2017.

[12] M. Wadhwa, N. Sharma, "Review of Agile Software Development Methodologies," International Journal of Advanced Research in Computer Science and Software Engineering, 3(2), 370-374, 2015.

[13] R. V Golhar, P.A. Vyawahare, P.H. Borghare, A. Manusmare, "Design And Implementation Of Android Base Mobile App For An Institute," International Conference on Electrical, Electronics, and Optimization Techniques, 3660-3663, 2016.

[14] L.J. Zhu, "Research and application of SQL Server in the trade management system," International Conference on Computer Research and Development, 3, 209-213, 2011, doi:10.1109/ICCRD.2011.5764282.

[15] A. Delgado, J. Sosa, "Mobile application design of geolocation to collect solid waste: A case study in Lima, Peru," International Conference on Electronics, Electrical Engineering and Computing, 1-4, 2019, doi:10.1109/INTERCON.2019.8853594.

[16] P.L. Alfonzo, "Implementación de SCRUM en el diseño del proyecto del Trabajo Final de Aplicación,” Scientia Et Technica, 19(4), 413-418, 2014, doi:10.22517/23447214.9021.

[17] A. Gómez, Aplicación Android para la empresa Travelling-Service, 2014.

[18] Z. Jiantao, P. Xuan, "Design and implementation of field staff management system on android mobile," International Conference on Instrumentation and Measurement, Computer, Communication and Control, 791-794, 2013, doi:10.1109/IMCCC.2013.176

[19] V.N. Vithana, D. Asirvatham, M.G.M. Johar, "Investigating the Issues of Using Agile Methods in Offshore Software Development in Sri Lanka," Studies in Computational Intelligence, 710(March), 515-523, 2017, doi:10.1007/978-3-319-56660-3_44.

[20] A. Delgado, "Social conflict analysis on a mining project using shannon entropy," International Congress on Electronics, Electrical Engineering and Computing, 3-6, 2017, doi:10.1109/INTERCON.2017.8079661.

[21] MINEDU, Propuesta de metas educativas e Indicadores al 2021 Lima, 2010.

[22] K. Kalimullah, D. Sushmitha, "Influence of Design Elements in Mobile Applications on User Experience of Elderly People," Procedia Computer Science, 113, 352-359, 2017, doi:10.1016/j.procs.2017.08.344.

[23] Balsamiq Studios, Quick and Easy Wireframing Tool, 2020

[24] M. H., "Notification System to Students using an Android Application," International Journal of Computer Applications, 140(1), 22-27, 2016, doi:10.5120/ijca2016909189.

[25] A. Srivastava, S. Bhardwaj, S. Saraswat, "SCRUM model for agile methodology," International Conference on Computing, Communication and Automation, 6, 864-869, 2017. 